\title{
El Slow Journalism en la era de la "infoxicación"
}

\section{Slow journalism in the "infoxication" era}

\author{
Samia Benaissa Pedriza. Universidad Complutense de Madrid (samia.benaissa@ucm.es)
}

Recibido: 01/09/2017 - Aceptado: 02/10/2017

\section{Resumen:}

El slow journalism surge como respuesta a la sobrecarga informativa generada por la aceleración del ciclo de producción de noticias en una era digital marcada por la aparición de nuevos operadores (redes sociales, agregadores de noticias). El estudio de casos practicado y la reflexión sobre la función que el "periodismo lento" debe ejercer en la actualidad indican que este sigue siendo útil para mejorar la calidad de los productos informativos. Por otra parte, se confirma la existencia de una demanda en alza de contenidos multimedia que analicen los hechos informativos en profundidad. Estas necesidades están siendo cubiertas por empresas informativas independientes de los grandes medios, más interesados en rentabilizar otros mercados de demanda masiva como las noticias breves de actualidad.

\section{Palabras clave:}

Slow journalism; Longform journalism; “infoxicación”; “fake news”; narrativas transmedia.

\section{Abstract:}

Slow journalism appears as a response to the information overload generated by the acceleration of the news production cycle in a digital era marked by the emergence of new operators (social networks, news aggregators). Both the study of cases practiced and the reflection on the function that the so-called "slow journalism" must exert today indicate that this type of journalism is still useful to improve the quality of information products. On the other hand, the existence of an increasing demand of multimedia contents that analyze the facts in depth is confirmed. That need is being covered by companies that are independent of the mainstream media, which are more interested in developing other mass demand markets such as latest news.

\section{Keywords:}

Slow journalism; Longform journalism; “infoxication”; fake news; transmedia narratives. 


\section{Introducción}

La actualidad digital está definiendo un nuevo marco informativo con noticias generadas por distintos operadores que no siempre son de origen mediático. La frecuencia a la que se produce, distribuye y consume información está alcanzando velocidades de vértigo desde que se instaurara la hegemonía del ciclo de producción de noticias de 24 horas a principio de la década de 2000.

La saturación informativa que genera este proceso y que soportan las audiencias digitales se traduce en actualizaciones continuas, en una escasez de fuentes consultadas y de hechos suficientemente contrastados, así como en la estandarización de las narrativas periodísticas. Desde hace una década son constantes las peticiones de expertos y profesionales de la información para incrementar los tiempos dedicados a producir informaciones publicables. Esta desaceleración del ciclo de producción de noticias mejoraría la calidad de los productos informativos, así como las condiciones de su recepción.

Es en este contexto donde surge el concepto de slow journalism, o "periodismo lento", como reacción a ese periodismo de celeridad, superficial y poco relevante. Son tan numerosas las opiniones sobre la necesidad de frenar la espiral de "infoxicación" (o intoxicación informativa) en la que se encuentran envueltas las actuales audiencias, que merece la pena reflexionar sobre el papel que esta vertiente periodística puede representar en ese proceso.

El presente ensayo se elabora cuando se cumple una década desde que los expertos académicos atribuyeran un nombre - "slow journalism"- a ese tipo de periodismo desacelerado, profundo y opuesto a la no siempre justificada urgencia informativa. En aquel momento la presencia de las redes sociales como nuevos agentes que participaban en el proceso de intercambio y difusión de información no era significativa. Diez años después, estos nuevos operadores, convertidos ya en nuevos actores de la comunicación, han logrado modificar radicalmente las normas de comportamiento, no solo de las audiencias, sino también del resto de actores y productores de información periodística.

Los problemas a que aludían los expertos hace una década -hartazgo e irrelevancia informativa, ausencia de rigor-se han agravado en los últimos tiempos, lo que justifica más que nunca un debate sobre el modo en que el slow journalism puede contribuir a modificar y mejorar esta situación.

La finalidad principal de este ensayo es conocer la posición en que se encuentra el slow journalism en la actualidad para hacer frente a este desafío. Por ello, los objetivos del ensayo están estrechamente relacionados con los nuevos retos, internos y externos, que el "periodismo lento" debe atender en el momento actual.

En primer lugar, se abordará el problema de la configuración del slow journalism como género propio en relación con otros ya existentes, posteriormente se debatirá su justificación en un sistema informativo dominado por la inmediatez y, por último, se evaluará la oportunidad de los costes que supone hacer este tipo de periodismo en las actuales empresas informativas. También se hará una reflexión sobre los géneros y formatos más adecuados para el desarrollo del slow 
journalism y sobre las mejores formas que tiene este periodismo de llegar a distintos tipos de audiencias en una nueva era digital.

A lo largo del ensayo se intentarán demostrar las siguientes hipótesis:

- El slow journalism ejerce una influencia positiva no solo en los géneros interpretativos sino también en los informativos (los más afectados por los efectos de la "infoxicación”).

- Se puede practicar en empresas informativas independientes que han adoptado un modelo de negocio viable y sostenible en el tiempo.

- Tiene capacidad para suscitar el interés de audiencias globales que expresan una demanda concreta por consumir este tipo de periodismo.

El slow journalism se inserta en una corriente de pensamiento más amplia que propugna una filosofía de vida moderna más sosegada en términos generales. Aplicada a un escenario mediático, influye en la concepción del tipo de periodismo que debe predominar en la era de Internet y de las redes sociales. Los principios del Slow Media movement se expresaron en el Slow Media manifesto (David, Blumtritt y Khöler, 2010: web) que propugna un periodismo de cocción lenta y de calidad visible en la producción, los contenidos y el diseño.

Sin embargo, intentar definir el concepto de slow journalism resulta una tarea ardua y controvertida. Las investigaciones empíricas desarrolladas a nivel académico son tan escasas (Drok y Hermans, 2016: 539-554) que solo se puede contar con las aportaciones teóricas efectuadas por los expertos (Gess, 2012:54-65; Greenberg, 2012: 381-393; Greenberg, 2015: 555; Le Masurier, 2015: 138-152) y con las opiniones vertidas por destacados profesionales de la información, basadas en la práctica.

La concepción más aceptada de slow journalism en la literatura científica se refiere a este como un género periodístico en el que se tiene en cuenta el estilo ensayístico y la forma extensa por la que se cuentan los hechos. Aunque hay quien lo considera más bien como una manera de enfocar las historias en base a una serie de principios y métodos (Drok y Hermans, 2016: 539-554).

El problema de investigación surge a la hora de intentar definir qué se entiende por slow journalism en una época en que la información mediática se difunde, recupera e intercambia no solo por los canales digitales habituales (webs de medios de comunicación) sino también por otros alternativos (buscadores, agregadores de noticias, plataformas digitales y, sobre todo, redes sociales). En ese sentido, el presente ensayo presentará una nueva aportación teórica, en todo caso subjetiva, sobre el concepto de slow journalism. La concepción que se propone, basada en la observación de casos concretos, se sumará al cuerpo doctrinal vigente y aportará un significado renovado del término slow journalism desde la perspectiva del nuevo ecosistema informativo. La definición incluye características presentes en otras contribuciones teóricas, aunque difiere en algunos aspectos de la idea de slow journalism apuntada por la doctrina hasta el momento actual. 


\section{Metodología}

Las reflexiones subjetivas expresadas en el presente ensayo se basan en opiniones informadas y documentadas sobre la base de un estudio no estructurado de casos, de resultados de investigaciones científicas practicadas por los expertos y de la lectura de artículos periodísticos que reflejan posturas de profesionales de la información sobre el tema objeto de reflexión. El estudio de casos se llevó a cabo en tres fases: selección de casos relevantes para el objeto de la investigación, análisis y posterior interpretación/discusión. Como no podía ser de otro modo, en este estudio prospectivo de naturaleza claramente exploratoria, la metodología empleada es cualitativa y está basada en técnicas de observación directa.

Las fuentes consultadas son de naturaleza primaria. Están constituidas por una muestra selectiva de informaciones publicadas en los medios de comunicación social durante los meses previos a la redacción del ensayo (diciembre de 2016 a octubre de 2017). También se han consultado informaciones relevantes publicadas en años anteriores (2007 a 2015), accesibles a través de hemeroteca. Las fuentes incluyen artículos, noticias, reportajes y entrevistas publicados tanto en medios digitales como impresos. Los criterios de selección de la muestra se basan en la relevancia temática, la actualidad mediática y la función ilustrativa.

\section{Resultados}

\subsection{Slow journalism, un término polémico}

“¿En qué consiste el slow journalism?” La pregunta formulada por Megan Le Masurier (2015: 138-152) revela bien cuál es el estado de la cuestión. En primer lugar, porque la alusión al término slow journalism se produjo por primera vez en el año 2007 y una década después no existe todavía un consenso académico sobre su contenido. Hace una década Susan Greenberg (2007: web) empleó la expresión para referirse a un conjunto de géneros narrativos emergentes como "ensayos, reportajes y otros géneros narrativos de no ficción en los que se dedicaba tiempo a investigar hechos y a comunicarlos con los máximos estándares de calidad periodística". En definitiva, la autora basaba el primigenio concepto de slow journalism en dos factores: el tiempo y la calidad. Algunos años después la propia Greenberg lo explicaba en esos términos:

“La primera vez que empleé el término 'slow journalism' en 2007 fue para referirme a las formas narrativas que conceden igual valor a los modos de contar los hechos que a su investigación. Mi contribución era original porque, según la teoría del 'management', el 'slow journalism' constituía un ejemplo de periodismo de amplio margen y elevada calidad, opuesto a los grandes flujos de noticias y situado en una posición intermedia respecto al periodismo convencional" (Greenberg, 2015: 555).

El factor tiempo parece ser consustancial para la mayoría de autores que han abordado el tema. Para Megan Le Masurier (2015: 143), este tipo de periodismo "no necesita un listado de características esenciales para ser calificado como lento. El 
término, al igual que el 'slow movement', significa más bien una crítica a los efectos que provocan las prisas en el periodismo". En España, Rosique-Cedillo y Barranquero-Carretero lo definen como el que "emerge como reacción a la tendencia periodística dominante a la novedad, la brevedad y la instantaneidad y que invita a repensar los tiempos necesarios para producir y consumir una información rigurosa, creativa y de calidad" (Rosique-Cedillo y Barranquero-Carretero, 2015: 453).

También la calidad y el estilo narrativo son elementos clave para autores como Erik Neveu o Don Belt. Neveu opone el "periodismo lento" a las noticias en bloque y lo asocia a la investigación y a la elección selectiva de los objetivos. También exige que sea "narrativo, justo con las fuentes y los lectores, participativo, orientado a la sociedad y, por último, que dé prioridad a noticias que no hayan sido contadas" (Neveu: 2016: 448-460). Belt, por su parte cree que el slow journalism depende de su fuerza narrativa, de la descripción de detalles y del tiempo empleado para investigar. Pero también relaciona el slow journalism con lo que caracteriza a "los grandes reportajes, el Nuevo periodismo, los géneros de no ficción, el periodismo explicativo, el inmersivo, el periodismo "gonzo", el etnográfico y el literario". Para Belt, en el slow journalism prevalecen la investigación en profundidad, la precisión, el estilo y el contexto sobre las prisas y las exclusivas (Belt, 2015: 547-562).

Finalmente, otros autores aluden a la extensión de las piezas informativas como característica esencial del slow journalism. Esto ha dado lugar a su vez a un tipo de periodismo que ha surgido de él: el longform journalism o "periodismo de larga duración" que ha sido definido por la doctrina como aquel en que "se emplean métodos periodísticos para investigar y escribir de forma independiente sobre gente, acontecimientos o temas de actualidad de forma tan extensa y larga como en un libro, para una amplia audiencia" (Ricketson, 2012). En la actualidad, el longform journalism, con textos de 1.500 palabras de extensión mínima, se desarrolla en el medio digital con tal intensidad visual (Lassila-Merisalo, 2014:1) y en ocasiones con tanta irrelevancia (Mahler, 2014: web) que, según algunos autores, incluso podría llegar a morir de éxito.

A primera vista, las características básicas que definen al slow journalism (calidad narrativa, extensión, mayor tiempo dedicado a investigar en profundidad) propuestas por la doctrina no parecen diferir demasiado de otras formas de hacer periodismo en el pasado. Los propios autores no tienen reparos en incluir bajo el paraguas del slow journalism al periodismo narrativo, cuyos orígenes se remontan al siglo XIX, al Nuevo periodismo surgido en Estados Unidos en la década de 1960 de la mano de Tom Wolfe, Gay Talese y Truman Capote, o al periodismo explicativo que dio lugar en 1988 a una nueva categoría de premios Pulitzer. Incluso se podría llegar a pensar que las citadas no son más que las exigencias básicas que todo tipo de periodismo debería cumplir en cualquier tiempo y lugar.

Se hace preciso encontrar, por consiguiente, ese factor X que defina de forma inequívoca al slow journalism frente a otros tipos de periodismo. Y ese factor no parece residir tanto en el tiempo o la extensión como en las formas o procesos. Por un lado, se admite que el slow journalism se oponga a la vertiente "rápida" del sistema informativo digital. Se trataría de toda 
aquella información de tipo "ready made", elaborada con textos cortos, vídeos poco editados e información básica que no supera la contenida en un lead y un titular.

Pero la longitud de una pieza informativa no puede condicionar su calidad narrativa en todos los casos. Un artículo de corta o mediana extensión puede haber requerido un tiempo largo de investigación, búsqueda y contraste de fuentes y de documentación. O estar perfectamente bien redactado y explicado. E igualmente, un reportaje en profundidad, elaborado durante semanas o meses, puede resultar carente de interés si no se ha elegido el enfoque correcto o el estilo narrativo más apropiado. De la misma opinión es Joshue Benton, director del Laboratorio de Periodismo de la Universidad de Harvard para quien "la extensión de un texto lo único que indica es que el artículo se debería abreviar" (en Albalad, 2015: 7-25).

Como afirma Benjamin Ball (2016: 432-444), el periodismo multimedia puede ser superficial o profundo, rápido o lento, corto o extenso. Y el slow journalism, cuyo desarrollo más completo se lleva a cabo en este medio, podría compartir todas estas características a excepción de la primera. El factor tiempo sin duda influye en la elaboración de las noticias ("se hacen buenas historias utilizando más tiempo. Y ahora no existen buenas historias”, Gay Talese, La Razón, 2012: web), pero no se trata de extender sine die el plazo de cierre de una noticia, sino de encontrar el tiempo más apropiado para elaborarla, editarla, publicarla y actualizarla.

\subsection{El ciclo de producción de noticias $24 / 7$}

"Nadamos en un mar de información," afirma Susan Greenberg (2007: web). Y se podría añadir que, a veces, incluso nos ahogamos en él. La introducción del ciclo de producción de noticias continuas las 24 horas del día, durante siete días a la semana, los 365 días del año cambió radicalmente los ritmos de edición de la información periodística. Y la consolidación de la presencia de las redes sociales en la vida cotidiana de los receptores ha contribuido a darle una vuelta de tuerca más a esta nueva forma de consumir información.

Claramente, el campo de cultivo del slow journalism no es Twitter, donde los medios practican un "periodismo" de titulares, ni Facebook, donde priman las reacciones en cadena a noticias reducidas procedentes de fuentes no siempre fiables. Las redes sociales, por su propia naturaleza, son apropiadas para difundir "breaking news" y propiciar un intercambio inmediato de opiniones sobre ellas pero no lo son tanto para dar cabida a productos informativos generados por el slow journalism.

Obviamente, se pueden compartir productos informativos que superen los 140 caracteres y participar en un debate en las redes sobre temas de calado informativo, pero es poco probable que estas acciones sigan el ritmo acuciante de la actualidad. La interacción será posible y deseable, pero -a excepción de las noticias de actualidad- se hará a un ritmo más pausado. 
En los últimos años, el aumento del ritmo en los ciclos de producción y recepción de las noticias se debe en gran medida al cambio en el consumo de información propiciada por el uso de las nuevas tecnologías. Los smartphones y tabletas no siempre favorecen una lectura calmada y reflexiva de la prensa sino el seguimiento de titulares y de noticias breves que se consumen en los pocos minutos que dura un trayecto en metro o autobús.

En cualquier caso, la impresión de que la rueda informativa gira demasiado deprisa no es exclusiva del siglo XXI. En los años sesenta del pasado siglo, el periodista Gay Talese ya se mostraba crítico con el "periodismo rápido":

"A veces parecía como si los periodistas tuviésemos una alianza con la industria de la comida rápida, porque al igual que ésta, preparábamos en el momento las órdenes de aquellos consumidores a los que les gustaba recibir la información y las ideas a medio cocinar” (Talese, 2012).

En la actualidad, autores como Martín, Torregrosa y Serrano (2010: 5-6) también se muestran en contra del "periodismo de la simultaneidad" que obliga a los periodistas a "reducir la novedad a los puros datos, al detalle". Y al igual que Honoré (2005) entiende que la filosofía "slow" no promueve la lentitud sino la búsqueda del ritmo adecuado, en este ensayo se sostiene la necesidad de encontrar una periodicidad apropiada para producir información digital. Lo que significa que se deberán aumentar los intervalos de tiempo para producir noticias y, por consiguiente, para consumirlas. Si bien es cierto que Internet también permite el consumo de información a largo plazo -noticias “colgadas" en la red por tiempo indefinido y que son recuperadas a posteriori gracias a los buscadores-, de lo que se trata ahora es que las informaciones raudas, dadas como primicia y con exclusividad, sean en todo momento relevantes para el receptor.

Para intentar frenar la saturación informativa generada por la profusión de noticias de agencia repetidas sin apenas cambios por los grandes medios es preciso invertir en el factor humano. De nada serviría reducir el ritmo de actualización de una noticia si esta no ha sido elaborada previamente según los principios de calidad, rigor y objetividad consustanciales a la actividad periodística. El ritmo frenético de actualización de las informaciones publicadas en las ediciones online de los medios de comunicación se debe en muchas ocasiones al hecho de que los propios periodistas se han saltado alguno (o incluso varios) pasos del proceso de búsqueda o de verificación de fuentes. Acuciados por las prisas se ven en la necesidad de tener que corregir datos imprecisos, confusos o falsos. Como afirman Rosenberg y Feldman (2008), "cada error cometido en la sala de redacción, al final es consecuencia de una ambición desmesurada por ser los primeros”.

Es en estos casos cuando los medios corren el riesgo de perder su credibilidad. Si un lector depositara su confianza en una determinada cabecera para seguir una noticia de actualidad y detectara errores o no obtuviese la información deseada por ser escasa, repetida o inexacta, seguramente acudiría de forma inmediata a la competencia, teniendo en cuenta que vivimos en un sistema informativo atomizado y extremadamente competitivo. 
Además, el periodismo que apuesta por estas prácticas acaba por estereotiparse y simplificarse en exceso (Drok y Hermans, 2016: 539-554) y los medios que lo defienden terminan por convertirse en irrelevantes. La intrascendencia se alcanza redactando noticias con titulares y palabras clave dirigidas a robots de indexación y no a lectores con forma humana. El estilo periodístico se ve afectado, la estructura narrativa y los contenidos también y, finalmente, la visibilidad que se pretendía obtener gracias a los algoritmos de los buscadores se pierde en la práctica por ofrecer informaciones demasiado simples, en absoluto destacables y poco atractivas en su configuración global.

La aplicación de los principios del slow journalism en la producción de noticias de actualidad podría mejorar esta situación. Un reportaje breve o noticia más completos, mejor elaborados, que incluyan recursos audiovisuales coordinados con la narración captarán mejor la atención y lograrán retenerla durante más tiempo. Los resultados registrados en ese sentido en medios audiovisuales así lo demuestran (Benaissa, 2012:28). Se trataría de organizar los datos en informaciones con mayor profundidad y a las que se les ha dedicado algo más de tiempo útil en su elaboración.

Algunos ejemplos de este tipo de piezas informativas se pueden encontrar en los reportajes de actualidad que publican los grandes diarios de información general en sus ediciones online ${ }^{1}$. En ocasiones, diarios como ABC o El País publican noticias elaboradas bajo los principios del slow journalism que incorporan podcasts o reportajes de corta extensión que incluyen gráficos de visualización de datos. Aunque esta práctica es más común y está más desarrollada en medios internacionales como The New York Times o Le Monde. Lo cierto es que los medios españoles prefieren reducir los tiempos de producción de noticias incluyendo vídeos de corta duración con información básica que reitera y no complementa lo expuesto en el texto, y ejercer el "periodismo lento" en géneros que no están tan pegados a la actualidad (reportajes descriptivos, en profundidad).

Como afirman Chung y Yoo (2008: 375-397), la actualización continua es una práctica apreciada por el público objetivo de un medio digital. Pero Megan Le Masurier también entiende que las prisas por producir información en tiempo casi real son las causantes de la pérdida de exactitud en las informaciones y de su falta de verificación (Le Masurier, 2015:138-152). La importancia que el slow journalism concede a la verificación de las fuentes actúa como escudo contra las informaciones difundidas tanto en medios de prestigio que han descuidado este proceso como a través de canales no mediáticos que

1 A título ilustrativo, véanse los reportajes de actualidad sobre los atentados terroristas cometidos en Europa y en la ciudad de Barcelona en agosto de 2017 publicados por las ediciones digitales de los diarios Le monde y The New York Times los días 18 y 19 de agosto de 2017. En el primero se informa sobre la práctica de los atropellos con vehículos como nueva forma de cometer atentados terroristas. El reportaje incluye gráficos de visualización de datos que contribuyen a explicar de forma rápida y eficaz aspectos que son tratados con mayor profundidad en el texto. En el segundo reportaje, relativo al atentado con atropello perpetrado en las Ramblas de Barcelona, se construye un breve relato cronológico que coordina con eficacia las imágenes y el texto de la narración. Las referencias web de ambas piezas se incluyen en la bibliografía de este ensayo. 
no han instaurado mecanismos de control específicos (redes sociales, plataformas como Yahoo, buscadores como Google y agregadores de noticias).

La situación descrita se produjo en un caso real: cuando el diario El País decidió darse demasiada prisa en publicar una exclusiva internacional en el año 2013 sobre el entonces presidente de Venezuela, Hugo Chávez. En aquella ocasión, el medio no hubiera tenido que sufrir un desprestigio si al publicar en portada una imagen del exmandatario siendo operado durante su enfermedad, hubiera llevado a cabo un proceso de fast-checking (o verificación) riguroso. La fotografía, que dio la vuelta al mundo y se publicó como una primicia, resultó ser falsa. El periódico tuvo que pedir disculpas por no haber verificado sus fuentes y enterarse a través de las redes sociales del verdadero origen de la imagen (un vídeo de un paciente anónimo publicado en YouTube) (El País, 2013: web).

La credibilidad periodística también se cuestiona debido a las noticias falsas que se publican y consumen de forma inmediata en las redes sociales. A pesar de que las fake news no son algo nuevo en el periodismo, su velocidad de propagación iguala ahora a la del resto gracias a estas nuevas plataformas de intercambio de información. La superabundancia informativa y el relajamiento en el control de las fuentes favorecen la circulación de fake news en redes sociales como Facebook, quienes reconocen estar haciendo esfuerzos para comprobar la veracidad de las noticias: "Si bien no escribimos las noticias que lees y compartes, reconocemos que somos más que un distribuidor de noticias. Somos una nueva clase de plataforma para el discurso público y eso significa que tenemos una responsabilidad para permitir que la gente tenga las conversaciones más importantes", afirman desde Facebook (ABC, 2016: web).

También Google y Bing están tomando conciencia de la importancia de luchar contra la difusión de noticias falsas indexadas en sus buscadores. Ambos han incorporado un nuevo código web (Claim Review) que permite identificar y resaltar las noticias en Bing, Google y Google News que han superado un proceso de fast-checking. Se trata del mismo código de schema.org (una iniciativa de etiquetado conjunta de Yahoo, Google y Bing creada en 2011) que ya han adoptado asociaciones de medios como PolitiFact o la web sin ánimo de lucro FastCheck.org

A pesar de que periodistas de prestigio como Christine Ockrent celebren que gigantes de las redes y de Internet estén comenzando a reaccionar (Le petitjournal.com, 2017: web), quizá habría que plantearse la pregunta de si es este su verdadero cometido. Porque los buscadores y redes sociales no son empresas periodísticas ni medios de comunicación social a pesar de que estén presentes y ejerzan un tipo diferente de función mediadora en el universo informativo.

El problema se agrava cuando son los propios medios de comunicación los que parecen estar haciendo una dejación de sus tradicionales funciones de verificación. Principalmente porque las noticias no contrastadas circulan en tiempo real por redes sociales que tampoco sienten la obligación de controlar de forma rigurosa la información que comparten sus usuarios. En todo caso, esta tendencia está siendo adoptada por muchos medios, incluido The New York Times quien ha decidido reducir su número de editores para contratar a más redactores con el fin de apresurar la producción de noticias y 
hacer frente a la competencia. El diario, que hasta ahora contaba con dos filtros de verificación de noticias pasará a tener solo uno (El País, 2017: web).

Sobre esta práctica reciente ya advertían Coddington, Molyneux y Lawrence (2014: 391-409): "los periodistas usan la tecnología para transmitir declaraciones y opiniones con rapidez en vez de dedicarse a comprobar los detalles". Pero afortunadamente, no todos los grandes medios comparten esta visión. Nick Petrie, responsable de información digital en The Times of London y The Sunday Times afirma que los medios siempre han sido verificadores de noticias y que este servicio que se presta a la sociedad es ahora más necesario que nunca. Además, rechaza "la publicación constante de noticias por el mero hecho de ser nuevas y no mejores" (Petrie, 2015: web).

La comprobación de fuentes, citaciones y declaraciones forma parte de las prácticas habituales del slow journalism, aunque es cierto que organizar un servicio eficaz de fast-checking no está al alcance de todas las redacciones. Principalmente, debido al coste que supone para los medios de tamaño reducido y con escasos recursos financieros. Y lamentablemente, no siempre garantiza que los resultados sean los esperados. Incluso publicaciones de prestigio en el ámbito del slow journalism como The New Yorker han protagonizado momentos bochornosos como cuando publicaron un avance del último libro de Gay Talese, El Hotel del Voyeur, sin haber comprobado suficientemente sus fuentes. Prácticamente todo lo que en él se contaba resultó ser falso (historias reales ocurridas en un motel de carretera de Estados Unidos, incluido un presunto asesinato que nunca tuvo lugar) al proceder de una fuente no fiable.

\subsection{Hacer buen periodismo cuesta dinero}

Muchas de las publicaciones que se dedican a hacer slow journalism son independientes de los grandes grupos mediáticos. No disponen de medios para investigar todo lo que quisieran o para costearse los servicios de un fast-cheker. Pero disponen de otras alternativas: buenos profesionales de la información, creatividad y visión empresarial para detectar un nicho de mercado que apenas está siendo cubierto por los grandes medios, interesados en desarrollar otros mercados informativos más rentables como el periodismo móvil. Dean Baquet, director de The New York Times lo confirma:

"Algún día, que ya ha llegado, casi todo el mundo va a ver las noticias desde el móvil. (...) El público sigue queriendo leer noticias largas, grandes reportajes, sigue leyendo lo tradicional, pero tenemos que ofrecer otras cosas también. El objetivo es que nos lean en este cambio que vive el mundo. Y para eso tienes que adaptarte al ritmo de la tecnología". (Baquet en XLSemanal, 2017: 18-19).

Mientras los grandes medios recurren a sus plantillas para investigar, verificar fuentes, editar vídeos o diseñar infografías creativas sin apenas coste añadido, las nuevas empresas informativas que se han especializado en hacer slow journalism buscan sus fuentes de financiación en mercados alternativos. 
El modelo de negocio que han adoptado estas nuevas empresas periodísticas de carácter independiente difiere relativamente en función de cada publicación, aunque todas coinciden en un punto: la voluntad de no depender de los ingresos por publicidad que caracteriza el funcionamiento de los medios tradicionales. Por un lado, porque pretenden preservar su independencia editorial, pero también porque consideran que el modelo de publicidad atenta contra la relación directa entre periodista y lector que se pretende establecer (Dowling, 2015: 530-546). Los ingresos provienen de las actividades de patrocinio, del crowdfunding, la publicidad nativa en Internet y las suscripciones. Las empresas de Estados Unidos, con otra cultura empresarial, tienden más a generar ingresos procedentes del patrocinio mientras que los medios europeos obtienen la mayoría de sus recursos del crowdfunding y, sobre todo en España, de las suscripciones.

Los casos de Jot Down y CTXT en España, representan una alternativa al modelo de negocio tradicional basado en la combinación de ingresos por publicidad y por venta de ejemplares. Ambas publicaciones se han especializado en slow journalism. La primera, una revista cultural digital nacida en 2011, edita también una revista impresa en la que no se incluye publicidad sino un reducido espacio (alrededor del 10\%) para patrocinadores (Breiner, 2015: web). La revista se distribuye mensualmente con la edición impresa de un medio de gran tamaño como El País. Jot Down factura en la actualidad un millón de euros anuales.

CTXT fue fundada por Miguel Mora, un experiodista de El País con el lema "orgullosos de llegar los últimos a las últimas noticias". La publicación es de acceso libre y se financia gracias al crowdfunding (llegó a recaudar de sus lectores casi 100.000 euros en un período de dos años) y a un porcentaje reducido de publicidad clásica (14.000 euros ingresados en el mismo período de tiempo). CTXT sigue en activo tres años después de su lanzamiento.

Pocas publicaciones pueden sostenerse únicamente con los beneficios de la venta de ejemplares o de suscripciones, aunque ese sea el objetivo final. De Correspondent, un medio holandés que comenzó su andadura gracias una campaña de crowdfunding, se financia con suscripciones pero acepta donaciones para pagar las traducciones de sus informaciones, mientras que los británicos Delayed Gratification ofrecen sus productos informativos de forma gratuita como forma de promocionar su revista impresa, de pago.

The Atavist, una revista estadounidense que solo publica una historia nueva al mes, obtiene ingresos de su publicación en diversas plataformas multimedia a través de una App, aunque sus principales fuentes de ingresos sean las suscripciones, la venta de informaciones por piezas y la venta de derechos a otros formatos. Por su parte, el agregador de noticias Longform obtiene el grueso de sus ingresos del patrocinio de la Universidad de Pittsburgh (Estados Unidos) pero solicita donaciones en su página web en la que también incluye algo de publicidad.

A pesar de la dificultad que supone financiar un medio de comunicación independiente en tiempos de crisis, la conclusión a la que se llega es que las publicaciones digitales especializadas en slow journalism han adoptado un modelo de negocio viable y dependiente fundamentalmente de la aceptación de su público objetivo. El éxito de cada negocio depen- 
derá en mayor medida de la calidad de sus productos informativos y de la visibilidad que logren darles en el ciberespacio que de los ingresos obtenidos por otros conceptos, como ocurre en el modelo tradicional.

Por otra parte, la reducida estructura organizativa y de costes de estos nuevos medios les permitirá tener una mayor capacidad para innovar y experimentar con nuevos productos y formatos informativos sin temor a fracasar.

\subsection{Los géneros del slow journalism}

Todas estas publicaciones y algunas más (Narratively, Aeon, ProPublica, Long Play, Ricochet, XXI, The New Yorker) son las que marcan la pauta a seguir en lo que se refiere a productos informativos y géneros periodísticos de slow journalism. Unas ponen el acento en la narrativa (The New Yorker, la francesa XXI), otras en la elaboración de un relato multimedia (The Atavist), pero todas se esfuerzan por renovar los géneros periodísticos en un momento en que, gracias a la tecnología, casi todo es posible.

Los grandes medios digitales parecen estar relegando la práctica del slow journalism al género del reportaje en profundidad, no demasiado despegado de un tema de actualidad pero renovado por la incorporación de una alta carga de elementos visuales (gráficos de datos, interactivos, tablas estadísticas, infografías). Las últimas tendencias informativas van incluso más allá e incluyen reportajes de periodismo inmersivo (reportajes grabados con cámaras de 360 grados, en 3D o realidad aumentada).

A pesar de que en un principio se pudiera pensar que los géneros más propicios para contar historias en profundidad son los interpretativos (crónicas y reportajes) -y de hecho, lo son- en el slow journalism también hay espacio para los géneros informativos y de opinión, e incluso para géneros híbridos.

En este ensayo ya se han comentado las posibilidades que ofrece el slow journalism para mejorar la calidad de las noticias y reportajes de actualidad de la prensa diaria digital, publicados incluso en ciclos de producción de noticias 24/7. Los géneros de opinión, capaces de condensar en pocos párrafos ideas y argumentos que incitan a la reflexión, son igualmente una buena opción para aquellos lectores exigentes con la información pero que no tienen tiempo de abordar historias que superen los diez minutos de lectura. El trabajo que lleva a cabo un analista político, un editorialista o un articulista de opinión puede ser igual de profundo, serio y riguroso que el efectuado por un reportero o un cronista. Y también requiere de tiempo para leer, documentarse, contrastar datos y fuentes, analizarlos reposadamente, encontrar argumentos y, finalmente, exponerlos de forma estructurada, con talento y creatividad.

Un ejemplo de cómo se puede hacer slow journalism con géneros de opinión es el vigente premio Pulitzer al mejor editorial. El galardón de 2017 se otorgó a Art Cullen, periodista fundador de The Storm Lake Times, un semanario local de Iowa (EE.UU.), por los editoriales publicados sobre la base de una profunda investigación emprendida a nivel regional. 
Las pesquisas llevadas a cabo por este modesto medio con tan solo 3.000 ejemplares de tirada, duraron dos años y tenían como objetivo denunciar la contaminación del agua y los intereses corporativos existentes en la agricultura de la zona. El jurado consideró que los artículos publicados a lo largo del tiempo sobre el tema revelaban "un trabajo de investigación tenaz, una extraordinaria competencia profesional y una sugerente narrativa" (Pulitzer.org, 2017: web).

El "periodismo lento" también opera con géneros híbridos. Las noticias y entrevistas reportajeadas son ejemplos de cómo exprimir el talento y las habilidades narrativas de los periodistas aunando lo mejor de varios géneros². Emplear un enfoque novedoso, un estilo personal, jugar con la estructura narrativa o hacer minería de datos (saber cómo encontrar historias ocultas en los datos) son algunas de las manifestaciones de esta creativa forma de informar. Si además se suman las posibilidades que ofrecen los actuales programas de software para editar y diseñar en modo multimedia, los productos finales generados por el slow journalism son susceptibles de alcanzar una más que notable calidad periodística. Estos productos serán luego editados en los distintos formatos disponibles en la era digital: desde aplicaciones para móviles hasta libros electrónicos, podcasts e incluso vídeo bajo demanda o streaming.

Matthew Ricketson (2015: 507-520) analizó el valor del "longform journalism", o "periodismo de larga duración” editado en formato libro, un tipo de soporte muy poco explorado hasta la fecha en lo que a slow journalism se refiere, pero que posiblemente debería comenzar a considerarse, al menos en determinados mercados nacionales.

Como apunta Erik Neveu, existe en Francia un conjunto de publicaciones digitales dedicadas al slow journalism que han inventado un género híbrido a caballo entre el magazine y el libro. Las revistas, en versión papel, se venden en librerías y no en establecimientos de prensa (Neveu, 2016: 448-460). La experimentación con géneros híbridos que nacen de este tipo de periodismo y se funden con la novela o el ensayo parecen estar suscitando también el interés de las grandes empresas de Internet como Amazon. Su editorial Kindle Singles permite publicar piezas informativas de hasta 30.000 palabras, lo que está fomentando la publicación vía $e$-book de un interesante número de libros de este tipo escritos por periodistas especializados.

Por otra parte, es conocido el interés que ha surgido en los últimos tiempos en Estados Unidos por los podcasts, que han terminado por colonizar los I Pods y teléfonos inteligentes de la población joven del país. Escuchar programas de radio de larga duración, entrevistas en profundidad y episodios semanales sobre las más variadas historias periodísticas se ha

2 Un ejemplo de noticia reportajeada que cumple los estándares del slow journalism es la que publicó el diario El País el 6 de marzo de 2012 sobre la intervención de la ONG Cáritas en “El Gallinero”, un poblado chabolista de Madrid: “¿Sabéis quién es el niño Jesús?”, “Sí, el hijo de la Lucía”. En el mismo sentido, el diario Público también publicó el 8 de abril de 2015 una entrevista reportajeada titulada "Vivir a pleno pulmón". En la entrevista a Raquel Nieto, una mujer diagnosticada con fibrosis pulmonar, se sustituyó la habitual fotografía de la entrevistada por un retrato ilustrado. En ambos casos los hechos se contaron con un enfoque noticioso alternativo y se empleó un estilo narrativo novelado. Las referencias web de ambas piezas pueden consultarse en el apartado bibliográfico de este ensayo. 
convertido en una nueva tendencia en el país-cuna del periodismo, aunque lamentablemente esta costumbre no parece haber arraigado por igual en todos los países. Quizá solo sea una cuestión de tiempo.

Posiblemente también con el tiempo, otros formatos audiovisuales como el streaming o la televisión bajo demanda sean más demandados por la audiencia para consumir reportajes y documentales elaborados bajo las premisas del slow journalism. Unos géneros que parecen haber desaparecido de las parrillas televisivas de las cadenas de información general en beneficio de las cadenas especializadas.

\subsection{Las audiencias del slow journalism}

En el mundo digital el valor de las audiencias se calcula en términos cuantitativos: cuántos cliks se han registrado en una página web, cuántas reacciones o comentarios ha generado una noticia, cuántas veces ha sido compartida en las redes sociales.

Pero desde un punto de vista cualitativo debería importar conocer cuáles son los efectos que en el receptor produce la información periodística publicada en Internet. A los medios que practican slow journalism les interesa que sus lectores comprendan toda la información, que sean capaces de recordarla porque les resulte útil y relevante y que el análisis de los hechos proporcionado les permita reflexionar sobre ellos y sacar sus propias conclusiones. Y si es posible, que las compartan. Los autores del Slow Media manifesto, David, Blumtritt y Khöler (2010: web) anuncian que este tipo de periodismo se dirige a "prosumidores", es decir a consumidores de información digital activos, lo que supone establecer con las audiencias una estrecha relación de escucha e intercambio de puntos de vista dentro de comunidades de usuarios en las redes sociales.

Como apuntan Barranquero y Jaurrieta (2016: 521-538), el slow journalism se dirige a "una audiencia local o global que se interesa por la información relevante". Lo que significa que lo que caracteriza al público objetivo del slow journalism no es su localización geográfica o sus preferencias temáticas sino su interés por conocer información que importe: datos nuevos no suministrados con anterioridad, enfoques informativos alejados del mainstream, análisis profundos de la realidad o hilos informativos que los grandes medios han dejado de seguir por las exigencias de la actualidad. La escasa presencia de este tipo de información en los medios digitales más visitados desplaza el interés de la audiencia hacia otros espacios donde poder publicar toda clase de artículos, reportajes y piezas informativas inspiradas en los principios del slow journalism. Webs especializadas, revistas digitales, blogs y agregadores de noticias reúnen a estas específicas comunidades de lectores.

Sin embargo, el slow journalism no tiene por qué dirigirse exclusivamente a una audiencia elitista, añeja y con formación académica superior. Un estudio llevado a cabo por Drok y Hermans (2016: 539-554) en los Países Bajos reveló que un 
considerable porcentaje de la población comprendida entre los 15 y los 39 años desearía que la información periodística fuese más “investigadora, inclusiva, cooperativa y constructiva”.

Otro estudio desarrollado por Lamb (2013:10-11) sobre la población estadounidense indica que el 44\% de los usuarios de tabletas las emplean para leer artículos de investigación periodística o reportajes en profundidad. Además, entre las mejoras que propondrían en la prensa digital se citaron "incluir más periodismo narrativo", "suministrar un listado de los expertos y recursos consultados" y "proporcionar formas de comentar los temas sugeridos en los artículos". En el ranquin de los aspectos más apreciados por los lectores de prensa digital, el suministro de contenidos extra y la inclusión de gráficos informativos y de visualización de datos ocuparon unas de las posiciones más altas.

Los resultados de los estudios empíricos practicados apuntan hacia la existencia de una notable masa de lectores interesados en el slow journalism. Se trata de un público acostumbrado a manejar dispositivos móviles que favorecen la interacción entre usuarios - muchos de ellos nativos digitales- y receptivo a las narrativas transmedia y multimedia. Este tipo de narrativas resultan apropiadas para practicar un buen "periodismo lento" ya que permiten enriquecer y renovar géneros tradicionales como el reportaje, la crónica o la entrevista en profundidad con elementos propios de la era digital. La información suministrada en capas (el background en un vídeo, los hechos en el texto, el análisis en una infografía, los sujetos de la información retratados en fotografías y la opinión expresada en ilustraciones) resulta así más atractiva y fácil de asimilar.

Las narrativas transmedia y multimedia favorecen además la apreciada interacción entre el público y los productores de la información periodística. Las audiencias participan en la narración, no solo visualizando gráficos, fotografías y vídeos o escuchando archivos de audio, sino también ahora a través de las nuevas posibilidades que ofrece la realidad virtual y la grabación de vídeos en 360 grados. Estas tecnologías permiten al lector disfrutar de nuevas experiencias narrativas más directas y personalizadas en el marco del periodismo inmersivo, un sector informativo aun en desarrollo, pero muy interesante para la evolución del slow journalism.

De cualquier modo, se aconseja siempre realizar un uso inteligente de estas nuevas tecnologías, apropiadas para enriquecer un relato informativo, pero que difícilmente podrán por sí solas construir una historia en toda su complejidad. Como afirma Martin Baron, director del Washington Post, "todas las herramientas tecnológicas del mundo no pueden sustituir al buen periodismo" (APM, 2017: web).

\subsection{Una nueva definición de slow journalism}

El análisis del contexto en que nace y se desarrolla el denominado slow journalism genera una serie de reflexiones sobre su naturaleza, su práctica profesional y el tipo de audiencia a la que se dirige. El funcionamiento del actual sistema infor- 
mativo y el desarrollo de nuevos productos informativos de base tecnológica reflejan la necesidad de revisar el concepto de slow journalism que la mayoría de la doctrina ha venido manejando hasta el momento actual.

Por consiguiente, y en base a lo expuesto con anterioridad en este ensayo, se propone una nueva definición operativa de slow journalism. A diferencia de lo que opina la mayoría de la doctrina, este no sería un género sino un proceso, entendido como un conjunto de prácticas profesionales, aplicable a todos los géneros periodísticos y que tiende a adaptar eficientemente los tiempos de producción y actualización de información periodística con el fin de aportar al lector información relevante, suficiente, con valor añadido y sobradamente contrastada. Su relevancia histórica se justifica por el particular clima de "infoxicación" generado por el intenso y veloz intercambio de flujos informativos en la era de Internet y las redes sociales. En ese sentido, pretender ser útil para combatir la desinformación propagada en estos nuevos espacios de intercambio de información mediática.

El slow journalism se concibe como una corriente transversal destinada a incrementar la calidad de los productos informativos digitales, añadiendo valor a través del contexto, el análisis y la interpretación de los hechos narrados de forma rigurosa. El slow journalism se beneficia de las innovaciones tecnológicas para renovar los géneros periodísticos y se dirige a una audiencia global, familiarizada con el uso de redes sociales y con el consumo de productos audiovisuales y multimedia.

La definición propuesta comparte con la mayoría de expertos el factor "calidad" al que se refieren en buena parte de sus aportaciones (Greenberg, 2007: web; Neveu: 2016: 448-460), y que debe estar necesariamente presente en los productos informativos resultantes del slow journalism.

Sin embargo, la nueva definición no coincide exactamente con las teorías de los académicos respecto a los factores "tiempo" y "extensión", aunque sí se alinea con la idea de "repensar" los tiempos de producción de información enunciada por Rosique-Cedillo y Barranquero-Carretero (2015: 453). Como ya se ha expuesto y argumentado con anterioridad, resulta perfectamente factible redactar textos breves que sean al mismo tiempo profundos y rigurosos y que hayan sido elaborados en un plazo de tiempo razonablemente corto (editoriales, artículos de opinión, reportajes de actualidad y noticias reportajeadas).

\section{Conclusiones}

El ritmo de producción y difusión de información digital a comienzos del siglo XXI representa un desafío para cualquier actor que participe en el actual ecosistema informativo. El ciclo de producción de noticias 24/7 sin duda constituye un reto para el slow journalism, pero este "periodismo lento" supone a su vez un acicate para aquellos que elaboran noticias instantáneas, mal redactadas, poco o nada contrastadas y cada vez más denostadas por su escasa calidad informativa.

Es innegable que las audiencias siguen demandando un espacio para el periodismo breve, casi de titular, que informe de lo esencial en poco tiempo. Esa parece ser la tendencia de futuro según las previsiones de los expertos, pero también 
deben reservarse espacios dedicados a tratar con profundidad y reposo los temas de la actualidad. Y no por una cuestión de ética profesional, sino porque existe una demanda clara y definida por parte de la audiencia.

El slow journalism, un género propio o un conjunto de prácticas periodísticas, según se mire, podría considerarse una evolución histórica de aquel periodismo narrativo cuidado con esmero de los años sesenta, pero en realidad es algo más que eso. Se trata de una nueva forma de hacer periodismo de calidad en distintos géneros y formatos tecnológicos, empleando el tiempo necesario para garantizar a la audiencia unos estándares de calidad óptimos.

Se ha demostrado que el slow journalism también se puede ejercer con eficacia en la vertiente rápida de Internet -la que obliga a la constante renovación de contenidos-, tanto en géneros eminentemente informativos como en géneros híbridos y de opinión. Aunque donde mejor se desarrolla es en su otra faceta, la dedicada al consumo lento y atemporal de información. La información que permanece más tiempo en el ciberespacio no la constituyen noticias breves sino textos largos y extensos. Así funciona el algoritmo de Google. Pero para elaborar informaciones con profundidad hace falta tiempo.

Las narrativas transmedia y multimedia propician el desarrollo y renovación de los géneros interpretativos, los utilizados con mayor frecuencia por el slow journalism. Ahora crónicas y reportajes permiten explicar hechos complejos con todo lujo de detalle en gráficos interactivos, en tres dimensiones o grabados con cámaras de 360 grados. Aunque invertir en estas tecnologías no resulta barato. Y supone una paradoja el hecho de que sean los grandes medios de comunicación los menos interesados en destinar recursos a financiar este tipo de periodismo, que sigue siendo demandado por el público.

El modelo de negocio que han adoptado las empresas informativas que se han especializado en slow journalism no difiere del de otros medios que operan al margen de los grandes grupos mediáticos. Sus ingresos provienen de la economía colaborativa, del patrocinio y de las suscripciones. A pesar de no contar con la estructura y los recursos de los grandes medios, han demostrado ser negocios viables, razonablemente rentables y atractivos en términos de audiencia.

El slow journalism es por tanto capaz de interesar tanto a un público general, que consume noticias de actualidad elaboradas con rigor y calidad, como a otras comunidades de usuarios agrupadas en torno a publicaciones especializadas que cuentan historias en profundidad, de forma original y atractiva, a través de contenidos multimedia que pueden ser compartidos y exportados a distintas plataformas.

El slow journalism sin duda cumple una función relevante en el actual sistema de información ya que actúa como dique de contención contra la desinformación, la saturación informativa y la circulación descontrolada de información no contrastada en Internet y las redes sociales. En todo caso, será interesante ver de qué modo evolucionará esta corriente periodística en un futuro que informativamente ya se vislumbraba hace medio siglo pero que definitivamente ya está aquí. 


\section{Referencias bibliográficas}

ABC. Artículo (16/12/2016): "El mecanismo de Facebook para atajar las noticias falsas: colaborativo y visual". http://www. abc.es/tecnologia/redes/abci-mecanismo-facebook-para-atajar-noticias-falsas-colaborativo-y-visual-201612161018_ noticia.html [Consultado 16/12/2016].

Albalad J. M. (2015): "Slow journalism para una nueva audiencia digital. El caso de Longform.org (2010-2015)", Revista de Comunicación, no 14, pp. 7-25.

APM (Asociación de la Prensa de Madrid). Artículo (26-01-2017): "Martin Baron, ante los desafíos de la profesión: 'Las cualidades que más necesitamos los periodistas son coraje y valentía'”. http://www.apmadrid.es/martin-baron-ante-los-desafios-de-la-profesion-la-cualidad-que-mas-necesitamos-los-periodistas-es-coraje-y-valentia/ [Consultado 26/01/2017].

Ball, B (2016): "Multimedia, Slow Journalism as Process, and The Possibility of Proper Time”, Digital Journalism, V. 4, n. 4, pp. 432-444.

Barranquero A. y Jaurrieta, G. (2016): "Slow Journalism in Spain. New magazine startups and the paradigmatic case of Jot Down”, Journalism Practice, V. 10 n 4, pp. 521-538.

Belt, D. (2015): “Slow Journalism and the Out of Eden Walk Pages”, Digital Journalism v. 4, no 4, pp. 547-562.

Benaissa, S. (2012): “La comprensión y retención del mensaje informativo por la audiencia de televisión”, Icono 14, vol. 3, pp. 202-227.

Breiner, J. (2015): “Cultural Publication Flirts with the ‘Dark Side’ in Spain”, Blog News Entrepreneurs. http:/ / newsentrepreneurs.blogspot.com/2015/07/digital-publication-flirts-with-dark.html [Consultado:13/02/2017].

Chung, D. S. y Yoo, C.-Y. (2008): "Audience motivations for using interactive features: Distinguishing use of different types of interactivity on an online newspaper", Mass communication \& society, vol. 11, no 4, pp. 375-397.

Coddington, M., Molyneux, L. y Lawrence, R.G. (2014): “Fact Checking the Campaign: How Political Reporters use Twitter to set the Record Straight (or not)", The International Journal of Press/Politics, vol. 19 nº 4, pp. 391-409.

David, S.; Blumtritt, J. y Khöler, B. (2010): Slow Media manifesto, Blog Slow Media, http://en.slow-media.net/manifesto [Consultado el 16/08/2017].

Dowling, D. (2015): “The Business of Slow Journalism. Deep storytelling's alternative economies”, Digital Journalism, vol. 4, nº 4 , pp. 530-546.

Drok, N. y Hermans, L. (2016): "Is there a future for slow journalism? The perspective of younger users", Journalism Practice, vol.10, nº 4, pp. 539-554.

146 | n²5, pp. 129-148 | doxa.comunicación

julio-diciembre de 2017 
El País. Noticia (06/03/2012): “Sabéis quién es el niño Jesús?” “Sí, el hijo de la Lucía” https://elpais.com/ccaa/2012/03/06/ madrid/1331067655_629460.html [Consultado el 17/08/2017].

El País. Artículo (24/01/2013): “La foto que El País nunca debió publicar”. https://elpais.com/internacional/2013/01/24/ actualidad/1359060599_118030.html [Consultado 15/08/2017].

El País. Noticia (01/06/2017): “The New York Times' reducirá el número de editores y elimina el defensor del lector”. http://cultura.elpais.com/cultura/2017/05/31/actualidad/1496256228_283175.html [Consultado 01/06/2017].

Gess, H. (2012): “Climate change and the possibility of “slow journalism”, Ecquid novi: African journalism studies, vol. 33, no 1 , pp. 54-65.

Greenberg, S. (2007): “Slow Journalism”, Prospect Magazine, www.prospectmagazine.co.uk/magazine/slowjournalism/\#. U06gsFV_uSo [Consultado el 16/08/2017].

- (2012). “Slow journalism in the digital fast lane”, en Lance, R. y Tulloch, J. (eds.): Global literary journalism: exploring the journalistic imagination. Nueva York. Peter Lang, pp. 381-393.

- (2015): “Editing, Fast and Slow", Journalism Practice, vol. 10, no 4, pp. 555-567.

Honoré, C. (2005): In Praise of Slow. San Francisco. HarperSan Francisco.

Lamb, Y. R. (2013): All the News That Fits on Tablets: An Analysis of News Consumption and Best Practices. Association for Education in Journalism and Mass Communications, Council of Affiliates. Second Annual Industry Research Forum. Washington, D.C. http://www.aejmc.org/home/wp-content/uploads/2013/08/Yanick-Rice-Lamb.pdf, pp.1-32.

Lassila-Merisalo, M. (2014): “Story First. Publishing Narrative Long-Form Journalism in Digital Environments”, Journal of Magazine \& New Media Research, vol. 15, no 2, pp. 1-16.

La Razón. Entrevista a Gay Talese (20/06/2012): “No se hace periodismo con Google y por e-mail” http://www.larazon. es/historico/3107-gay-talese-no-se-hace-periodismo-con-google-y-por-e-mail-TLLA_RAZON_465556 [Consultado 07/04/2017].

Le Masurier, M. (2015): “What is slow journalism”, Journalism practice, vol. 9, nº 2, pp. 138-152.

Le Monde. Reportaje (19/08/2017): “L’attaque à la voiture bélier : un mode opératoire de plus en plus fréquent en Europe” http://www.lemonde.fr/les-decodeurs/article/2017/08/19/1-attaque-a-la-voiture-belier-un-mode-operatoire-de-plusen-plus-frequent-en-europe_5174211_4355770.html [Consultado 19/08/2017]. 
Lepetitjournal.com. Artículo (24/04/20017): “Christine Ockrent. Echanges sur l'évolution des médias et sur le fonctionnement de notre démocratie à quelques jours des élections présidentielles françaises” http://www.lepetitjournal.com/singapour/accueil-singapour/actualite/277387 [Consultado 24/04/2017].

Mahler, J. (2014): "When “Long-form” is bad form”. The New York Times. https://www.nytimes.com/2014/01/25/opinion/ when-long-form-is-bad-form.html [Consultado 03/10/2017].

Martín, M.; Torregrosa, M. y Serrano, J. (2010): “Un periodismo sin periodos: actualidad y tiempo en la era digital, en Periodística y web 2.0: hacia la construcción de un nuevo modelo". XII Congreso de la Sociedad Española de Periodística (SEP). Universidad Cardenal Herrera (Valencia), pp. 1-14.

Neveu, E. (2016): “On not going too fast with slow journalism”, Journalism Practice, vol. 10. no 4, pp. 448-460.

Petrie, N. (2015): “The year news slow down”, Blog NiemanLab http://www.niemanlab.org/2015/12/the-year-news-slowsdown/ [Consultado: 06/04/2017].

Público. Entrevista a Raquel Nieto (08/04/2015): "Vivir a pleno pulmón” (http://www.publico.es/espana/trasplante-pulmon.html). [Consultado 16/08/2017].

Pulitzer.org. The Pulitzer Prizes. Noticia (11/04/2017): “The 2017 Pulitzer Prize Winner in Editorial Writing. Art Cullen of The Storm Lake Times, Storm Lake, IA" http://www.pulitzer.org/winners/art-cullen [Consultado 17/04/2017].

Ricketson, M. (2012): Australian Journalism Today. South Yarra. Palgrave Macmillan, Education Australia.

(2015): “When Slow News is Good News: Book-length Journalism's Role in Extending and Enlarging Daily News", Journalism Practice, vol. 10 n 4, pp. 507-520.

Rosenberg, H. y Feldman, C.S. (2008): No Time to Think; The Menace of Media Speed and the 24-hour News Cycle. Nueva York. The Continuum International Publishing Group.

Rosique-Cedillo, G. y Barranquero-Carretero, A (2015): "Periodismo lento (slow journalism) en la era de la inmediatez. Experiencias en Iberoamérica”, El profesional de la información, vol. 24, no 4, pp. 451-462.

Talese, G. (2012): Vida de un escritor. Madrid. Alfaguara.

The New York Times. Reportaje (18/08/2017): "La ruta del atentado terrorista en la Rambla de Barcelona" https://www. nytimes.com/es/interactive/la-ruta-del-atentado-terrorista-en-la-rambla-de-barcelona/?action=click\&clickSource=inicio\&contentPlacement=1\&module=toppers\&region=rank\&pgtype=Homepage [Consultado 18/08/2017].

XLSemanal. Entrevista a Dean Baquet (Magazine semanal del 14 al 20 de mayo de 2017): "Necesitamos periodistas valientes más que nunca", no 1.542, pp. 14-20. 